\title{
Los sonidos de la "narcocultura". Exploración a propósito de la expresión musical
}

\author{
Tanius Karam Cárdenas ${ }^{1}$
}

\begin{abstract}
Resumen
En este texto exploratorio en el que presentamos algunos conceptos procedentes de los estudios semióticos y discursivos en la caracterización de la expresión musical y su relación con la narco violencia. El objetivo es identificar algunas áreas de estudio tanto de los corridos - que ha sido el género más estudiado- como de otras expresiones que sirven para estudiar la relación música-narcoviolencia, tal es el caso del narco rap y la presencia del narcotráfico en otros géneros de la música popular. A este momento el trabajo es principalmente documental, con el que completamos un acercamiento a la letra y a la relación que éstas tienen con sus condiciones de producción y escucha

Abstract

In this exploratory text in which we present some concepts from semiotic and discursive studies in the characterization of musical expression and its relationship with narco violence. The objective is to identify some areas of study of both the corridos -which has been the most studied genre- and other expressions that serve to study the music-narcoviolence relationship, such as narco rap and the presence of drug trafficking in other genres. of popular music. At this moment the work is mainly documentary, with which we complete an approach to the letter and the relationship they have with their production and listening conditions.
\end{abstract}

\section{Palabras Clave}

Música popular, Discurso mediático, Narco cultura, Violencia, Narco Rap

Keywords

Popular music, Media speech, Narco culture, Violence, Narco Rap

${ }^{1}$ Universidad Autónoma de la Ciudad de México

\section{Debate en torno a una noción problemática}

A partir de la llamada "guerra contra el narcotráfico" del ex presidente Calderón, se dieron varios fenómenos de tipo cultural y mediático como la abundancia informativa, el incremento de la industria editorial, boom de (narco) series, telenovelas, películas entre otros. Hay que señalar por otra parte que este tema generalmente no aparece aislado y se encuentra asociado a otros asuntos como inseguridad, corrupción, violencia, hechos de sangre, escándalos políticos lo que da una red particularmente atractiva para la espectacularización audiovisual. Si bien el periodo del ex presidente Calderón potenció la agenda mediática, policiaca y política en torno a los asuntos del narcotráfico, el problema y su representación mediática dista de ser reciente. A lo que asistimos es a un nuevo entorno técnico e industrial caracterizado por el aceleramiento de las producciones y una oferta diversificada, multimedial en el mercado.

Entre las expresiones mediáticas del narcotráfico, sin duda la música es una de las más representativas. Pululan los narco corridos repetidos hasta el hartazgo y de los que no resulta casual el interés de varios académicos e investigadores por lo llamativo de sus letras y las nuevas formas de violencia en este género musical. Parte del éxito del corrido se la fuerte tradición que lo respalda, así como su articulación a prácticas sociales igualmente muy arraigadas en la vida 
cotidiana de las comunidades no solo en regiones mexicanas, sino también en los EE.UU. Los narcocorridos tampoco son algo formalmente nuevo ya que históricamente ha habido corridos que cantan a hechos polémicos o hacen apología de bandoleros sociales como lo señala la famosísima antología del investigador poblano Vicente T. Mendoza (1954). Ahora bien, lo más novedoso en la expresión musical no es tanto el narco corrido como el "narco rap" arraigado igualmente en la línea de la estética "gangsta" y el hip hop y que han sido escasamente estudiados por la academia. Más aún, como señalamos rápidamente al final de nuestro texto, otros géneros de música popular como la trova, igualmente han reaccionado a la presencia de esa violencia que al margen de la interpretación que se haga, es imposible no atender.

En nuestra concepción del fenómeno musical asumimos una perspectiva comunicativa. La música no es solo "enunciado" (los componentes básicos del discurso musical: melodía, armonía, ritmo) sino un tipo práctica discursiva inserta en condiciones de producción, transmisión y recepción. En su metodología con frecuencia algunas perspectivas culturalistas e interpretativas se reducen al comentario de los códigos lingüísticos, y omiten las dimensiones de la comunicación musical que debe incluir desde los componentes físicos de la música (timbres, volúmenes, intensidades, duraciones) hasta la construcción particular de identidades socio-culturales que la escucha y recepción general. En la actual ecología caracterizada por la convergencia mediática, la letra-música no se difunde aisladamente, y a ella se asocian bailes, vestimentas, imágenes, expresiones corporales y faciales que se aprenden en películas o videoclips, en conciertos o fiestas, en documentales o programas de televisión y que se tiene un aprendizaje complementario en remediaciones como YouTube o en los nuevos modos de escucha a través de "Spotify".

En el título de nuestro trabajo asumimos una noción expresamente problemática: "Narcocultura" que sin duda invita a la polémica porque esta noción puede parecer poco ética algunos; o peor aún, pensar que lo "narco" puede generar alguna expresión con valor cultural. El concepto "cultura" lo usamos desde una perspectiva más semiótica y simbólica en donde las expresiones no son tanto "productos del espíritu" o "realizaciones materiales de un grupo social" sino las definimos como conjuntos de redes de significación producidas con una intencionalidad, dirigidas a unos grupos sociales y dentro de unas condiciones de producción-recepción. A través de estas redes productores y destinatarios interactúan, y de alguna manera "completan" su experiencia al interpretar esos materiales y contenidos ${ }^{1}$ (Cf. Geertz 1997). Por "narcocultura" queremos decir "expresiones simbólicas" generadas desde diferentes "regímenes de representación" 2 a propósito del narcotráfico dentro de una red de subtemáticas como violencia, corrupción, inseguridad, delincuencia organizada, etc. El tema de la "narcocultura" lleva a tal nivel que incluso el estado mexicano tiene incluso su propia definición (Secretaría de Seguridad Pública, 2009, p. 4 y ss) e incluso le asigna lugar de origen (Badiraguato, Sinaloa): llama la atención esta caracterización lo que puede entenderse también como una necesidad de regular y controlar la interpretación de un fenómeno cuanto más sencilla es su explicación ${ }^{3}$. Dentro de conceptos también problemáticos podemos referir lo señalado por Omar Rincón (2013) que usa un término susceptible de una discusión mayor: "forma narco", por medio del cual designa expresiones generadas directamente de quienes participan directamente en el negocio del narcotráfico (capos, sicarios, familiares, mujeres) y se manifiesta en casas, tumbas, aditamentos, accesorios que a nivel social al ser reconocidos permiten la identificación

\footnotetext{
${ }^{1}$ Tenemos en mente el capítulo 3 del conocido libro de John B.Thompson (2002, capítulo 2) en el que revisa los conceptos de cultura, incluido el de Clittford Geertz, pero que considera limitado en tanto, por ejemplo, no presta mucha atención a los condicionante y efectos de poder en las expresiones simbólicas. Thompson adelante su propuesta denominada "estructural" (que diferencia de "estructuralismo"), y que de hecho nos invita reflexionar y discutir si pudiéramos definir estos regímenes de representación sobre el narcotráfico, a su manera, también como una "formación simbólica" (Thompson, 2002, p.203).

${ }^{2}$ Este es un concepto que adaptamos originalmente de la semiótica básica de Daniel Chandler (Semiotic for beginners, capítulo 2) y que parte de la idea que los signos no existen independientemente del sistema en el que se usa. La idea de realidad se construye a partir de los lenguajes, donde podemos identificar "marcadores de modalidad", es decir paquetes sígnicos, recursos, tipos, moldes, argumentos que nos ayudan a reconocer e interpretar las distintas expresiones de la narcoviolencia, provengan éstas del narco mundo o del cine de autor. Estas "claves" permite interpretar el mensaje al hacer "creíble", "verosímil" dentro de sus códigos de construcción. Siguiendo a Hodge y Krees (Social semiotics, 1988) esta "modalidad" se basa en el estatuto de credibilidad en el mensaje; en la confiabilidad que genera entre quien lo produce y lo interpreta.

${ }^{3}$ Dentro de la producción académica varios trabajos han abordado el tema de las narrativas oficiales para explicar el tema del narcotráfico, también como una forma de controlar la representación que se tiene de él, como ejemplo podemos citar Zavala (2018); Lujan María "La insoportable levedad del discurso. Timos epistemológicos en la construcción mediática de la narcoviolencia" (En Mitologías Hoy. 2016 diciembre Vol. N 14, 25-40) y Escalante, Fernando El crimen como realidad y representación. (México. COLMEX, 2012).
} 
de alguien como "narco". Rincón analiza la fuerte crítica procedente de la estética burguesa y define lo "narco" como un tipo "contracultura ante la modernidad", lo que también podemos definir como un particular (des)encuentro entre niveles culturales: el premoderno de los narcocorridos, las formas tradicionales, el mundo del campo y lo fuerte de las relaciones familiares; el moderno manifestado a través de una industria trasnacional y con distintos niveles económicos; y el posmoderno de la gran relatividad moral de sus acciones, del hiperconsumo y las fascinación por lo fugaz y lo inmediato.

En cuanto la relación narcotráfico-narcocultura, Gómez y Figueroa (2013) la conciben con un vínculo de interdependencia: se puede hablar de "narcotráfico" pero sin "narcocultura"; empero a la inversa la fórmula no opera. Para otros ensayistas como Zavala (2018) hablar de "narcocultura" supone una terrible reducción ideológica que conlleva la despolitización del narcotráfico y lo reduce a una reproducción de los argumentos oficiales y gubernamentales sobre este problema. También los historiadores acusan de cierto malestar al circunscribir el tema de las drogas en el boom reciente, ya que la "droga" es una noción más amplia que no puede restringirse a la moda discursiva del siglo XXI ni mucho menos al periodo del ex presidente Calderón. Los historiadores nos recuerdan que las drogas son un fenómeno más antiguo de lo que se cree, como prueban algunas expresiones culturales, entre ellas, las alusiones a la marihuana de la célebre canción popular "La Cucaracha"4.

El término "narcocultura" cabe entonces con algunas aclaraciones en el sentido de definirlos como un conjunto muy heterogéneo y extendido de expresiones simbólicas a propósito del narcotráfico articulada a redes semánticas ya señaladas y ancladas en diversas tradiciones enunciativas dentro del mundo literario, musical, político algunas de ellas de mucho arraigo popular, como el tema de los corridos, pero también las telenovelas y otros. La "narcocultura" se configura a partir de modalidades o "regímenes de representación” entre las que se incluyen (sin que éstas sean todas) (a) las versiones oficiales con su épica y su forma de informar, sus boletines de prensa y sus rituales de información donde se le ve muy "teatral"; (b) el discurso informativo, las noticias que vemos o leemos con imágenes de asesinados, descabezados, las fuentes

\footnotetext{
4،La cucaracha, la cucaracha / ya no puede caminar, / porque no tiene, porque le falta, / marihuana que fumar".
}

informativas que se toman, las formas de dramatización de los noticieros, la red de analistas; (c) los registros audiovisuales a partir de producciones de bajo y alto costo, comerciales o semi-estéticas, transmitidas por televisión o por sistemas de contenidos; (d) "Régimen investigativo", relacionado con el segundo, aunque centrado en prácticas para generar un conocimiento más sistemático, objetivo y que puede asumirse en documentos académicos o reportajes de prensa; e) los regímenes de la cultura popular como el corrido, pero también algunas formas de religiosidad popular o géneros mediáticos de mucho arraigo como las telenovelas; (f) el "régimen ‘poético' o 'estético”, que tal vez sea el más problemático de todos y donde generalmente sus productores buscan algún tratamiento en el lenguaje de las artes plásticas o visuales como lo podemos reconocer en el fotoperiodismo de Fernando Brito, alguna película de Amat Escalante, o colección de la artista chicana Carolyn Castaño.

\section{Exploración por la relación entre violencia y música.}

Uno de los aspectos que llama la atención de las expresiones musicales del narcotráfico es la alusión a la violencia, sobre todo en las letras y acciones que realizan los cantantes, en los videoclips o en las pocas entrevistas donde los intérpretes y grupos hablan de su trabajo. Para la comprensión de la violencia hay que reconocer las expresiones específicas, pero sobre todo considerar la dimensión sistémica que genera condiciones específicas de materialización, la relación entre la violencia objetiva y subjetiva, entre la macro y lo micro (Foucault). En el caso de la música generalmente la relación con la violencia se estudia en ciertos géneros, estilos, letras de canciones que contienen un vocabulario con algún tipo de violencia (por ejemplo, violencia de género) o contra algún grupo racial, sector social. Es frecuente encontrar textos contra algunos estilos o géneros como el reguetón, algún tipo de "rock pesado" o ahora los narcocorridos, entre otros. Steven Feld (citado por Ochoa, 2006) va más allá al proponer una categoría particular ("acustemología de la violencia”): conocimientos musicales o sonoros (práctica de voz, sonidos, escucha, sistemas de silenciamiento o lo que no se dice ni expresa, por ejemplo, el tema de las víctimas) que surgen en contextos de violencia. La música en todo caso es un medio que permite intensificar e interiorizar emociones, sentimientos 
y da una consistencia particular a las representaciones y asociaciones que la expresión sonora nos puede generar. $\mathrm{Si}$ bien el tema de las letras es un componente importante, como señalamos es insuficiente para dar cuenta de la expresión comunicativa vehiculada a través de la música. Brown y Volgsten (2006) realizan distintos análisis sobre los usos de la música y la manipulación a través de ésta como mecanismo de control; no es que un tipo de música se pre-condicione más que otras, sino que la música puede reforzar códigos de comportamiento y en el nivel del contexto y sus contenidos; por ello la música también puede ser terapéutica, aunque en otra dimensión su uso puede orientarse para infringir dolor de modo violento.

La música como violencia se expresa en el volumen, en el contenido ideológico de sus letras, su uso para torturar a las personas o para ejercer el control específico de grupos. Los ejemplos son múltiples, entre ellos, por mencionar uno de los más antológicos en su uso en la película de Stanley Kubrik Naranja Mecánica, en donde la música cumple una función particular en la vida de los grupos violentos como en los intentos por "curar" a estos sujetos.

En las ciencias del lenguaje una de las categorías más usuales es la de Acto de Habla ${ }^{5}(\mathrm{AH})$ que como en el caso de las tricotomías de la semiótica básica de Ch. S. Peirce ${ }^{6}$ pueden ayudarnos para explorar las posibilidades básicas en la descripción que relaciona música y violencia. Tomando el primero componente del $\mathrm{AH}$ podemos reconocer en el enunciado musical una dimensión locutiva el tipo de acciones (asesinatos y descuartizamientos) y relatos todo aquello se

\footnotetext{
${ }^{5}$ Conocido es conocido la expresión tiene su origen dentro de la filosofía del lenguaje anglosajona de corte pragmáticas. Las referencias inequívocas son del filósofo inglés John Austin (Cómo hacer cosas con las palabras, 1962) y su discípulo norteamericano John Searle quien escribe poco años después Actos de habla, 1969. Es la unidad más pequeña que se realiza por medio de la lengua que realiza una acción (hablar es una forma de actuar va decir Austin) y su finalidad es muy pragmática, modificar y regular el comportamiento de los hablantes.

${ }^{6}$ Siempre las menciones esquemáticas y cortas no hacen justicia de este importante filósofo, lógico creador no solo de la semiótica contemporánea, sino también del pragmatismo que es la primera corriente filosófica de importancia en los EE.UU. y con ella se cifra un tipo de concepción de la comunicación y la cultura donde la regulación a los efectos particulares, las actuaciones y los usos del lenguaje son fundamentales tal como se ve en la Escuela de Chicago, de impronta pragmática también. El concepto de "dimensión perlocutiva" en la teoría del os Actos de Habla, y de alguna manera en la tercera dimensión de la triádica sígnica peirciana (interpretante... no intérprete y que se define como el efecto generado por la relación significa representamen-objeto y que puede ser éste otro signo) guarda una relación pragmática porque subraya la importancia de la consecuencia, la "puesta en escena" (término no usado por estos autores) en la comprensión (lógico), en el lenguaje o en la comunicación.
}

expresa por la letra, pero también por el cuerpo, la vestimenta, los tatuajes, con la mirada que se refuerza muy efectivamente en los narco-videoclips (también comparativamente poco estudiados), ya que como explica Martin Daugthry en el libro citado, la música se escucha no solo con los oídos, sino con el cuerpo. La segunda dimensión es la ilocutiva, donde podemos hacer el repertorio comunicativo de la intencionalidad musical y cuya principal diferencia es la que divide la apología de la que no la es, pero también la que describe o da cuenta, la que quiere "quedar bien" con alguien, etc. en la enunciación musical la intencionalidad de los enunciadores y enunciatarios puede ser diferente. Finalmente, la dimensión perlocutiva, y esa vasta posibilidad de efectos sociales, las consecuencias cognitivas, actitudinales que podemos asociar, con las expresiones mediáticas del narcotráfico; quizá sean pocas las personas que quieren matar a alguien después de escuchar un narco corrido, pero a nivel representacional desarrollar una tendencia que justifica las acciones vehiculadas por las letra, los videoclips, lo que otros dicen, etc.

La relación música-violencia es diversa y en semiótica básica podemos concederle distintos funcionamientos donde vemos no tanto qué significan los signos, sino cómo se relacionan los signos para generar el sentido. De esta manera si reconocemos, por ejemplo, a nivel de semiótica básica general y usando la célebre tricotomía de Peirce la descripción básica de la significación musical parte de la primeridad o relación de los signos sonoros y musicales consigo mismos en sus elementos físicos que podemos asociar primero como cualisigno en las propiedades del sonido (volúmenes, altura, intensidad, timbre) que son parte de una particular emisión, como cualquier narco corrido donde ahí los reconocemos (sinsigno) (el sonido de ciertos instrumentos) gracias también a leyes particulares (legisigno) (los códigos en las formación de estrofas) que lo hacen inteligible y que permiten estudiarlo en sus regularidades. En cuanto su secundidad o relación de los signos con su objeto, reconocemos el valor icónico de ciertos sonidos cuando identificamos la imitación de armas (hechos en muchos corridos, mediante el golpe de la batuca con alguno de los tambores de la batería), o bien la superficie sonora se plaga de sonidos específicos (sirenas de ambulancia, gritos, voces y otros); la música tiene un funcionamiento indicial, que nos lleva escuchar o reconocerlo somo señal de 
detonación de acciones violentas y que por ejemplo cuando asociamos la narco-música con una región podemos asociarlo como "música del norte" (“conjunto norteño", "música de banda"). Finalmente la tercera tricotomía de la terceridad o de las relaciones del signo con el interpretante que asociamos a un conjunto de procesos mentales y acciones que va desde el reconocimiento potencial de las instrucciones violentas en las canciones (palabras, guiños, expresiones) y de su eventual aplicación ( rema); pasando por el reconocimiento de indicaciones adicionales (la violencia contra algunas personas en particular, por ejemplo "integrantes del bando enemigo") (dicente) a su formulación y ejecución que puede ser interpretado por destinatarios o grupos sociales particulares en un sentido ( argumento). Esta exploración debe completarse con su posibilidad aplicativa en casos específicos que dejamos asentado en lo general. Aquí hemos querido a manera de exploración, señalar algunos componentes que nos permitan adentrarnos al sistema musical donde van integrados procesos que señalamos a partir de la tricotomía básica de Peirce.

\section{Comenzar por lo sabido: la centralidad del narco corrido}

Pensar en música, violencia y narcotráfico hace pensar en los corridos que ha devenido en el epicentro musical y donde permite recuperar las funciones narrativas con una larga tradición como la del corrido que ha mostrado la capacidad de adaptarse y sobrevivir a una anticipada carta de defunción que uno de sus principales estudiosos Vicente M. Mendoza (1954) pensó que podría darse en la década que publicaba su famosa antología y en la que dedica un apartado para hablar de los "corridos sociales"; pero el corrido siguió, se adaptó, acompañó las transformaciones musicales, siguió su vida propia en la música regional (del norte, pero no únicamente), dio cuenta del contrabando, la vida en la frontera, los migrantes, y finalmente el narcotráfico. Ramírez Pimienta ${ }^{7}$ para quien el narco corrido surge en los treinta con

\footnotetext{
${ }^{7}$ Algunos de sus varios textos sobre el tema Ramírez-Pimienta, Juan (2010) "Sicarias, buchonas y jefas: perfiles de la mujer en el narcocorrido". En The Colorado Review of Hispanic Studies, Vol. 8-9, Fall 2010-11, pp 327-352; - (2007) "Narcocultural a ritmo norteño: El narcocorrido ante el nuevo milenio". Latin American Research Review 42, 2; ProQuest, pp.254-278; _ (1998) "El corrido de narcotráfico en los años ochenta y noventa: un juicio moral suspendido". The Bilingual Review/ La Revista Bilingüe. XXIII.2 (May-August 1998): 145-156. Puede verse también su blog https: //narcocorrido.wordpress.com/2008/05/31/elna rcocorridoestrategiasydefinicionesparasuestudio/
}

el corrido "El Pablote" dedicado a quien le decían "el Rey de la Morfina", en estos primero corridos no había alabanza alguna de los personajes, se inició como lamento y querían dejar una enseñanza; en ocasiones algunas de estas canciones se hacían desde la cárcel en el que el cantante se lamentaba e incluso asumía cierta culpabilidad en sus acciones; también en estas letras no se mencionan armas, ni se apela a una idea más amplia del narcotráfico; la función emotiva adquiere una dimensión importante en el acto de habla del lamento.

En sendos ensayos Carlos Monsiváis (2004, 1999) explica cómo si los autores de los corridos revolucionarios tenían alguna idea de la rima y la acústica del romanticismo y cierta intuición del don metafórico, en el narco-corrido no hay instrumento técnico mínimo. Comenta algunas canciones como "El corrido del pacífico", del que reconoce que más que la celebración del delito, difunde la ilusión de la sociedad donde los pobres tienen derecho a las oportunidades delincuenciales de "los de Arriba". La representación del narcotraficante es la del atuendo excéntrico y ese conjunto de signos de todo mundo reconoce cuando ve a una persona en camionetas polarizadas o con excesivo atuendo de joyas. Lejos de suponer una pérdida de valores, para Monsiváis la emergencia del narco es el episodio más grave de la criminalidad neoliberal, y manera como necesariamente para extenderse se necesita la protección de las mafias del poder.

El narco corrido comenzó a tener una presencia importante a partir de la década de los setenta, pero no son propiamente los primeros corridos que aluden a cuestiones ilegales o paralegales, o que cuentan hazañas de bandidos y policías. Desde los inicios el corrido fue un espacio discursivo para dar cuenta de expresiones, hazañas y osarías de muy diversos personajes, entre ellos figuras de la Revolución, bandidos, contrabandistas, migrantes, héroes populares, etc. Los narco-corridos son más que letras e historias, se trata de expresiones vinculadas a una cultura, a un modo particular de entender el mundo donde se subrayan hazañas, hechos sobresalientes, instrucciones a partir de casos; así mismo las letras épicas y narrativas facilitan la transmisión de una cierta concepción de la vida y la muerte, la legalidad y el delito, los amigos y los enemigos. Los narco-corridos vehiculan sentidos, difunden imaginarios ${ }^{8}$, difunden relatos, recrean modos de

\footnotetext{
${ }^{8}$ Es necesario comentar que usamos este difundido término en cierto sentido psicoanalítico como formas de deseas y proyectar éstos en
} 
vida o concretizan aspiraciones (Cf. Mondaca, 2012: 49); están incorporados a la vida cotidiana y son parte del paisaje de las ciudades, sobre todo a un "tipo" de norte mexicano.

El corrido y también el narco corrido han sido objeto de muy distintos estudios, la lista es inmensa (entre centenas de trabajos, Valenzuela, 2002; Mondaca, 2004, Wald 2001, Edberg, 2004; Burgos, 2012). Los enfoques varían: aproximaciones histórico-sociales, o bien aplicaciones de los estudios de género, que es algo que ha llamado la atención a no pocos especialistas: por ejemplo, el trabajo de Giacomello y Ovalle (2006) quienes discuten si los narcocorridos trasmiten o no visiones contrahegemónicas de la mujer, o si estamos ante una nueva perspectiva hipersexualizada propia del mundo masculino traslapada en un aparentemente empoderamiento de la mujer. También los trabajos de Mondaca y Valenzuela hacen tipologías de letras para reconocer temáticas dominantes, estereotipos, etc. Una mención particular son los trabajos de Burgos quien critica la perspectiva representacional que se centra en las letras. Otra línea de trabajo ha sido el análisis historiográfico hecho Ramírez Pimienta.

Junto con el análisis de las letras, es importante el de los grupos, los usos sociales para comprender cómo se pasa del tímido consumidor que se lamenta del uso de la droga a la apologiá del "jefe de jefes". En esa trayectoria dentro de los muchos grupos cabe señalar — no porque sea el mejor, pero sí el de mayor visibilidad comercial — a los "Tigres del Norte" que desarrollan el "corrido de contrabando", el "corrido de frontera" como el famoso "Contrabando y Traición" (1973) antes de llegar a su famoso disco Corridos prohibidos (1989); viene después “Jefe de jefes” (1997) y el soundtrack de "La Reina del Sur" (2002) que luego devino un signo convergente y multimedial de la "narcocultura" e incluyó corrido, película, fotografía, videoclips, serie de televisión. En 2006 tenemos noticia del surgimiento del autodenominado

pensamientos y acciones del sujeto. El término tiene esa perspectiva más psicoanalítica que propiamente cognitiva o representacional. El imaginario lo vínculos aquí con la proyección del deseo que reviste de una complejidad al proceso por el cual se hace eso. Cornelius Castoriadis acuña el término "imaginario social" donde subraya la dimensión institucional de este proceso y de manera lejana puede asociarse con "mentalidad", "conciencia colectiva"; si bien con frecuencia se le quiere usar como sinónimo de "representación", creemos esta construcción es imprecisa porque el proceso interno es distinto. En nuestra argumentación queremos subrayar la manera en que la música nos pone en cuenta con lo que deseamos, y cuando escuchamos música también proyectamos deseos, aspiraciones, sentimientos (por ejemplo si recordamos alguna persona).
"Movimiento Alterado" que marca un hito porque es elaborado desde EE.UU. por dos hermanos de origen sinaloense que logran posicionar a cantantes, grupos y bandas y usan para ello recursos ya de nuevas tecnologías como plataformas, videoclips, sistema de venta por internet; los cantantes se asumen como parte de esa marca y el "movimiento" que en realidad es un sello musical que al principio se centra en este tipo de corridos interpretados por varones, luego incorpora a las vocalistas mujeres. Durante algunos años dicho "movimiento" se hace sinónimo del narco corrido contemporáneo, pero no es el único ya que hay casos de otros intérpretes que también cantan estos tipos de corrido.

Si partimos de concederle una centralidad al corrido en el modo "movimiento alterado", podemos reconocer algunos rasgos en su construcción significativa como discurso musical: a nivel de melodía quizá lo más evidente en el código lingüístico son las letras, las expresiones y los sociolectos lo que no supone pretensión rítmica o letrística alguna; a nivel interpretativo hay un aceleramiento, la rapidez en los puentes musicales. Tal vez la parte más estable de la tradición es el ritmo (tiempos binarios); la disposición de los instrumentos es la de la música regional, tanto en la agrupación tipo noreste (acordeón, guitarra, bajo y batería) como en la llamada "banda sinaloense" que ayuda acentuar el carácter bailable aun cuando la finalidad de los corridos originalmente no se baila. A este tipo de agrupaciones la industria musical denomina genéricamente como "música norteña"9 y también "música grupera" más confuso aún. El elemento más sobresaliente de los narco corridos son sus letras explosivas con descripción de hechos violentos y relatos diversos de sus narcotraficantes, sicarios, o integrantes de su familia. A ello se suma el tipo de comunicación corporal que vemos en la película o el videoclip, donde la construcción del enunciador-personaje en ocasiones se le confunde como si fuera una fuerza de élite de la policía (siempre vestidos de negro, muchas armas, pasamontañas, etc. $)^{10}$. En estas letras no todo el modo extradiegético — como en los corridos interpretados por los "Tigre" en los ochenta,

\footnotetext{
${ }^{9}$ Que es equívoco porque parecería que hay un solo norte, cuando hay "distintos nortes" de tradiciones musicales distintas. Cuando hay diferencias evidentes por ejemplo entre la "banda sinaloense" y el cuarteto convencional que utiliza el grupo regiomontano, por no hablar de estas expresiones vernáculas y folklóricas que incluso no llevan instrumento como el caso de la "canción cardenche" en la región de La Laguna.

${ }^{10}$ De los varios ejemplos uno de los casos más emblemáticos es del dueto Los Buchones de Culiacán y de sus narcocorridos "La orden", "El comando suicida del mayo", entre otros.
} 
sino que el sujeto enunciativo asume la primera persona: abunda el relato desde el punto de vista del personaje y con ellos podemos conocer estados interiores, afectivos y mentales descritos por el mismo sujeto ${ }^{11}$. Cuando el relato no es en primera persona, hay un sujeto plural que se construye como alguien inteligente y que razona (“.... pa' mentes / expertas siguen avanzando con inteligencia”), con capacidad de acción y respuesta y en todo momento una caracterización positiva en su organización, estructura, gusto lo que redunda en la fuerza como sujeto del discurso. Cierto tipo de acciones son parte de un repertorio más amplio que puede relacionarse con distintos tipos de violencia, aunque la más explícita es la diversidad de acciones que generalmente implican la muerte; en las letras escuchamos comandos, sicarios valientes, historias de asesinatos, juegos de traiciones, mujeres que participan en el negocio dentro de un repertorio que emula, describe y valora los signos, valores, objetos y detalles del narco mundo.

De las varias operaciones discursivas, una de ellas es la "metaforización corporal" que se caracteriza por "esencializar" al "nosotros" evocado a partir de "espíritu de la enfermedad", solo que ésta — como ya se hizo de la violencia- no se representa con valores negativos, sino como algo que se comparte, "se contagia". "Estar enfermo" supone un estado particular que tiene una dimensión física, mental y la cual es deseable en el mundo imaginario promovida por estas canciones. En ocasiones, a nivel metadiscursivo, se puede apelar al destinatario con la expresión "raza enferma", a la manera de un vinculo que se interpreta positivamente, e integra a los participantes en la aspiración de las "ventajas" que ofrece dicho estado.

\section{El narco rap como sistema emergente. Testimonios y letras}

A pesar de lo anterior, no todo es corrido y en la relación música- narcoviolencia es necesario incluir lo que está pasando en torno al "narco rap" del noreste el cual apenas es mencionado incluso por quienes han estudiado el corrido. La historia del rap es muy distinta a la del corrido, viene de otra tradición, además de ser un fenómeno muchos más reciente que emerge entre la difícil realidad en los barrios de afro americanos de Nueva York y que nación

\footnotetext{
${ }^{11}$ Pensamos en número del "Komander" como "El taquicardio", "Borracho y escandaloso",
}

no solo con un componente de marginalidad sino de clara confrontación con las instituciones, de hecho en algunas modalidades de hip hop dicha condición se radicaliza. El Rap como muchos ritmos musicales, originalmente fue un fuerte signo identitario de los grupos que lo produjeron que luego, a través de los medios masivos, vive una cierta difusión lo que de alguna manera suaviza su rasgo socialmente más confrontante. El "rap" se considera una derivación del "funk", asociado al "hip hop" y se caracteriza por una sincopa muy marcada y percutida que tiene largos textos que se cantan con fuerte inflexión rítmica donde el juego entre las silabas de lo que se dice; la letra parece emerger de la propia sugerencia rítmica, así ésta cumple una doble función donde a diferencia del corrido, se obligado al "rapero" a una cierta versificación que frecuentemente puede ser producto de la improvisación lo que añade un componente de dificultad y reconocimiento cuando la rima es efectiva, coherente, original, etc. Por las características del discurso verbal la letra puede ofrecer distintas informaciones a los que se añade recursos paraverbales y formas prosódicas; la letra se adapta a cualquier temática: desde situaciones intrascendentes hasta temas de violencia, sexo, machismo. En el narco-rap también podemos encontrar expresiones a favor de cárteles, advertencias a grupos, crítica al Estado y las instituciones, recordatorio de integrantes de la banda, aspectos actitudinales del propio sujeto discursivos (por ejemplo "Pollo y Conejo" de Cartel de Santa). El rap parece un sistema con mayores subdivisiones a las del narco corrido porque se ha alimentado de fusiones y estilos como "rap reaggae" o el "chicano rap", el "rap hardcore" o el "gangsta rap"12 que en su estética parce el más cercano al "narco rap" y guarda una relación cercana.

El centro del narco rap mexicano ha sido el noroeste y principalmente Monterrey, aunque junto con Nuevo León también está arraigado en algunos centros urbanos de Tamaulipas. Para Mejía (2016) el rap ya existía antes de la llega de la "guerra contra el narcotráfico". Quizá el primer nombre que sobresale en la escena del rap en la capital neolonesa es el rapero tejano Juan Gotti que participaba originalmente en eventos controlados por la autoridad. Mejía relata su experiencia como integrante del grupo "Mexican

\footnotetext{
12 "Gangsta" es una palabra usada en la jerga rapera de EE.UU. y deriva de gangster, definido éste como alguien perteneciente a una "ganga" o pandilla. El término también puede hacer referencia a un gunman o pistolero, aunque el gangster es un criminal de profesión.
} 
Fusca" cuyo primer álbum (2008) es Semper Ascendens. Antes del boom del narcotráfico, las letras del rap regio versaban sobre conflictos callejeros, uso de drogas, violencia, protestas contra el gobierno, entre otros; si bien al principio no se estilaba hacer mención explícita a grupos del crimen organizado, hay raperos que lo hacían desde entonces. Según Mejía al estabilizarse la guerra y tener el "control de la plaza" un grupo criminal, buscan a raperos para que les escriban canciones y relaten la vida de alguien, den cuenta de las acciones o incluso hagan una canción como manda por el santo de su devoción. En 2012 el integrante de "Mexican Fusca" reconoce se da un incremento de la violencia y con ello asume una cierta necesidad de dar cuenta de los hechos, como lo reflejan en la canción "La Lupe"13 donde vemos una clara descripción de los hechos y donde a diferencia del narco corrido centrado en los personajes, es frecuente que el rap opte por ambientes y descripciones más amplias. Es relevante aclarar que si bien las canciones de dicho grupo hacen referencia a cuestiones del crimen organizado, no es propiamente narco rap, pues de acuerdo con Olvera (2018) y Malcomson (2019), el narcorap son canciones que se elaboran por comisión, que no es el caso de Mexican Fusca ${ }^{14}$.

Otro testimonio el de "Babo" vocalista del grupo "El Cartel de Santa" (ECS), establece una oposición entre quienes le gustan los corridos y este "nuevo narcotráfico" representado por el rap. Para este cantante, en 2010 los narco rapistas más importantes eran el "Mono" y el "Darius", originarios de Nuevo León, zona controlada por los “Zetas". Como en el caso de corridistas, los raperos aceptan encargos y en muchas de sus letras puede haber una clara defensa y apología de estos grupos. También podemos encontrar relatos de diversión, parranda y lujos como se ve en el "gangsta rap" de EE.UU. El rap de ECS tiene como un añadido, la incorporación de temáticas propias de migración, indocumentados y lo que por otra parte es también una influencia de los ritmos afroamericanos. El grupo ECS es un fenómeno particular de difusión y funcionamiento en los circuitos comerciales, con conciertos, participantes en bandas sonoras de películas y videoclips de mediana calidad además de premios "disco de

\footnotetext{
13،Guadalupe, la tierra de nadie / entras y no sales, entre calles mis carnales... / . . a asaltos, secuestros, colgados, decapitados / policías corruptos: una bala en el cráneo / el crimen no para y llega con más fuerza / ya le metieron la chaira a la pinche Alcadesa".

${ }^{14} \mathrm{Fe}$ de erratas, agosto 2020.
}

oro" (2016) y "disco de platino" (2017); con distintos tipos de letras caracterizada por niveles donde el sujeto enunciador hace referencia al perfil del participante en un grupo o describe elementos del contexto.

En las notas de prensa que hemos podido recabar el narco rap deviene como una alternativa a jóvenes, sobre todo en el noreste. Por ejemplo, el caso de otros cantantes, esta vez de la ciudad fronteriza de Reynosa Tamaulipas en donde "Cano" (Alejandro Coronado) y "Blunt” (Mauro Vázquez) no llegan a 30 años, estás rapados y llenos de tatuajes; se conocieron desde niños, vivieron la influencia de los corridos, como todo oyente en la región, pero de adolescentes se sintieron más cómodos con la influencia de la música estadounidense y del rap en particular. Dentro de sus influencias reconocen a "Doctor Dre", "Lil Wayne", "Eminem" exponentes del rap y hip hop de EE.UU.; también mencionan a "señor Tego Calderón” de Puerto Rico ubicado en el estilo "gangsta". En algunas canciones como "Comandante Aguililla" realizan el tradicional acto de habla a favor en este caso de un lugarteniente del Cartel del Golfo en el que narran sus hazañas y advierten a sus enemigos de nuevas acciones contra ellos. En "Pinches Enwilados" (2011) es un ejemplo de exploración de sociolectos y donde en lugar de componente típicamente narrativa aquí estamos antes una descripción más amplia de una actitud, una disposición del lenguaje, quizá por ello no resulta casual un "bit" más lento al de otros números del grupo. Finalmente otro caso es el de la canción "Reynosa la Maldosa"15 (2010) donde vemos la construcción del espacio; se reivindica la ciudad fronteriza en la que se respira un tipo de atmósfera; en pocos trazos el narrador no solo da cuenta del ambiente sino del tipo de relación que tiene con la ciudad a la que dice querer. Estos tres ejemplos, nos dan cuenta de la diversidad temática y el modo discursivo, al menos de sus letras, que no se reduce al relato y nos permite adentrarnos a la subjetividad del sujeto de enunciación.

En el blog "Narcoviolencia.com.mx", en entrevista de marzo de 2015, estos raperos toman distancia del "Movimiento Alterado" y de cualquier movimiento de narco corridos. "Cano" y "Blunt" reconocen que han sido hostigados

\footnotetext{
15 "Somos puro Reynosa un chingo de malandros / pura gente mafiosa lo sufres o lo gozas, / Reynosa la Maldosa, la calle es peligrosa, póngaseme trucha, pura gente maldosa / [...]"Bienvenidos a mi reino, Reynosa querida / donde a diario la gente se rifa la vida / gente que pesa, gente que te vuela la cabeza / ándate con cuidadito o de balas te atraviesan / cuerpos mutilados y tirados al canal /demasiada maldad pa' caber en un penal".
} 
por la autoridad, a la que no le gusta se hable con tanta familiaridad de traficantes y líderes. Si bien de manera declara - lo que no siempre pasa con los narco-corridista — reconocen componer por encargo y tener vínculos con integrantes de los cárteles. Estos cantantes no dan conciertos públicos, solo cantan en eventos privados. Si bien la temática central es el narcotráfico en sus canciones también pueden aparecen otros problemas sociales, lo que dan a sus letras una superficie de cierta protesta social que facilita las audiencias (no necesariamente narcotraficantes) sintonicen con su estilo y tratamiento y se sienten identificados con las letras. Los narco rapistas han señalado que el cantar no es solamente libre apología; sus jóvenes cantantes lo ven como una fuente de ingreso. al respecto la obra de José Juan Olvera (2016) describe la economía del rap como una "economía en resistencia" que la ubica más que algo "creativo" o "alternativo" y en el que no solamente incluye a quienes están más cercano a los grupos armados, sino sencillamente jóvenes que se quieren expresar, y una de cuyas temáticas es el narcotráfico.

\section{5. "Apéndice trovero"}

La relación entre narco violencia y música en el México contemporánea tiene todavía posibles aristas de estudio y a pesar de las cuestiones reiterativas como el lenguaje explícito o la descripción de acciones violentes, tiene otras posibilidades que permiten reconocer el tipo de interiorización de la narcoviolencia a través de estas expresiones. Así como reconocemos no todo es corrido en la narco-música, vemos al rap con consistencia propia y una mirada propia al mundo del dolor, de la dificultad y la sobrevivencia en las calles.

Dentro de nuestra búsqueda de expresiones musicales, encontramos un ejemplo en la trova mexicana que vale su mención en este ejercicio exploratorio, justamente por su particularidad. La trova como movimiento lírico se encontró asociado a cuestiones políticas y sociales cuya expresión más famosa entre los sesenta y ochenta del siglo pasado fue la "nueva trova cubana" que a veces se le define — de manera imprecisa- como música de "protesta", y donde encontramos sobre todo menciones no tanto a violencia específica como social, política y estructural, por ejemplo, en las denuncias contra el imperialismo de EE.UU. ${ }^{16}$ Estamos ante un tipo de expresión que por una parte parece contradecir el carácter épico de la tradición trovera en una región donde es más frecuente la denuncia social contra el abuso de autoridad, las dictaduras, las consecuencias de la pobreza o la desigualdad en término generales, que la descripción o menciones a hechos específicos. A nivel melódico e instrumental la trova posee un contenido lírico que tiene como aspiración una expresión más cercana. Originalmente la idea de "trova" hace pensar en la dupla guitarra-voz, como en el caso del cantante mexicano que comentamos, y que desde ahí siempre busca, a nivel letrístico la exploración de un estado de ánimo y a nivel musical un tipo de canción, generalmente sin mucha exploración armónica.

En el CD Tiempo Ventanas(2014) Fernando Delgadillo trovador originario de las afueras de la ciudad de México, incorpora un número, un poco a contracorriente de su producción. "Gente Armada" describe a los grupos delincuenciales lo que resulta una extraña novedad en su repertorio musical. Este número inicia con marcas metadiscursivas e incorpora distintas voces periodísticas que sirven como antecedente al inicio de la melodía, y también anticipa lo que vamos a escuchar: la violencia, la inseguridad, la presencia mediática, etc. "Gente armada" quiere reflejar un ambiente de violencia generalizada, y apunta algo más, cuando a nivel argumentativo propone que la violencia no se puede acabar con más violencia ${ }^{17}$. Esta balada se construye a partir de un pequeño collage de reacciones, en las que más que al narcotráfico — sí referido en la segunda parte de la canción- es el clima de violencia generalizada, las actitudes y el efecto de naturalización de la violencia en la sociedad. El sujeto enunciativo apela a una "razón", por encima de una realidad, el narcotráfico que no ha cambiado en lo general ("Y es que nunca cesó /la venta de estupefacientes"), por ello no acepta la violencia como solución. En la obra la voz narrativa no da cuenta de su propio dolor, ni tampoco es una descripción del horror social (aludido en el metadiscurso

\footnotetext{
${ }^{16}$ Puede escucharse "Canción urgente para Nicaragua" de Silvio Rodríguez

17 "Y a mí me confía un amigo / que ya mañana mismo / se consigue una pistola / que ya es cosa de tirar para vivir,/ que no piensa ponerle a nadie /fáciles las cosas, dice: /“¡Yo voy a defenderme, / yo no me voy así!” / Que si su vida viera amenazada, /se las iban a ver con gente armada. "Se ha dicho que acabar / con la ignorancia del consumidor, en vez del traficante, solucionan de verdad; / pero hay quienes trafican / y otros secuestran y matan / para probar lo que creen / que hay que probar. "Quisiera yo poder ver / más allá de lo aparente / para probarme a cantar por la razón. / Y es que nunca cesó / la venta de estupefacientes, / aunque es un día más que avanza / la violencia en la nación".
} 
sonoro inicial), sino que reacciona a la voz de otro. En la letra aparece un antagonista supuestamente un "amigo" de la voz narrativa quien supuestamente está de acuerdo en la lucha del ex presidente Calderón traducido en la formula "combatir la violencia, con violencia". El "amigo" sirve al narrador para hacer dos operaciones: presentar lo "lejano" (la situación social) como lo "cercano" (lo dicho por alguien a quien se aprecia, definido en la letra como "amigo"). El narrador se demarca del "amigo" y "aleja” al "próximo". El diálogo resumido por la voz narrativa funciona como un indicador del tema "violencia" en nuestras sobremesas y relaciones personales.

La canción de Delgadillo se hace eco de ese clima que justamente los productores derivados del "narcotráfico" por una parte reaccionan a una interpretación del entorno, y por la otra fortalecen un cierto clima de opinión. La música facilita una cierta interiorización no solo referencial, sino sobre todo anímica, actitudinal. La diversidad y aparente "realismo" de algunas expresiones nos da la impresión de aparente novedad, lo cual hemos explicado a propósito del "Movimiento Alterado". Ante este tipo de narco corridos, la llamada "música grupera" venía ganando terreno en el gusto urbano o de las grandes ciudades, las letras en otros órdenes de expresión (relaciones amorosas, pareja, sexualidad) igualmente venían ampliando el gradiente semántico; la permisividad respecto a la presencia social de los narcotraficantes fueron antecedentes que consolidaron las condiciones de posibilidad de un gusto que igualmente fue cambiando. A ello se añade la facilidad y la posibilidad de consumos más selectivos por ejemplo para quien busque canciones sobre narcotráfico.

En la recepción musical, la música popular permite una amplificación a expresiones y estados mentales que facilita la empatía de los sujetos discursivos y enunciativos (los cantantes, los grupos), se tiene acceso a otro tipo de experiencia. El oyente puede tener la impresión que el corrido o el rap describen los hechos tal cual son, y dar un valor de verdad que por supuesto no aparece en la música comercial, los medios convencionales, ni mucho menos en los discursos oficiales. Este valor de cercanía supone una implicación cognitiva y afectiva hacia estos materiales. El narco rap y narco corrido se anclan en tradiciones previas que facilita la inserción de grupos previamente participantes del género, que extienden el "gusto" hacia asuntos ya existente, pero sin la centralidad y divulgación del narco mundo en la letra de canción. Las canciones facilitan un determinado conocimiento del mundo social y del narco mundo, dentro de usos sociales distintos entre sí.

Entre las semejanzas y diferencias del narco rap y los corridos vemos por ejemplo cómo el primero sí permite una denuncia social que no aparece en los narco corridos contemporáneos; ambos géneros coinciden que algunos de sus actos de habla pueden ser la apología de los sujetos involucrados en el negocio del narcotráfico. En cuanto sus claras diferencias, no hemos encontrado narco rapistas mujeres, mientras que en el narco corrido, si bien originalmente los grupos eran masculinos ha habido el caso de varias cantantes femeninas.

El narcotráfico no es un asunto que solamente anide en expresiones marginales, rurales o contraculturales, sino que puede transmutar, con signos incómodos a expresiones sociales y de corte estético donde inevitablemente el narcotráfico adquiere un matiz particular, por ello quizá la incomodidad del concepto "narcocultura" criticado, con razón, por considerar que de manera voluntaria o no, hace apología del narcotráfico, legitima explicaciones oficiales de la realidad y sobre todo tras la espectacularidad y aparente novedad, obnubila el reconocimiento de las razones constitutivas del narco estado y la necro política, base simbólica en estas expresiones donde el Estado, en el mejor de los casos, es el problema mismo. En medio de la perplejidad, la sorpresa o el entretenimiento estas explicaciones poco importan a muchos consumidores quienes dentro de lo accesible del consumo, se regodean entre el morbo, el simple placer, o una pequeña dosis de resignación.

\section{Referencias}

Astorga, L. (2005). El siglo de las drogas: el narcotráfico, del Porfiriato al nuevo milenio. México: Plaza y Janés.

Brown, Steven y Volgsten, Ulrik (Eds.) (2006) Music and Manipulation: On the Social Uses and Social Control of Music, New York, London, Berghahn Books, 2006.

Burgos Dávila, C. J. (2012). Mediación musical: Aproximación etnográfica al narcocorrido. Barcelona: Facultad de Psicología. Universidad Autónoma de Barcelona. Tesis de Doctorado. Documento en línea 7 
de junio 2015, disponible en http://tdx.cbuc.es/bitstrea $\mathrm{m} /$ handle/10803/129901/cjbd1de1.pdf?sequence $=1$

Edberg, Mark C. (2004) El Narcotraficante. Narcocorridos and the Construction of a Cultural Persona on the U.S.-Mexico Border, Austin, University of Texas Press.

Geertz, C. (1997). La interpretación de las culturas, trad. Alberto L. Bixio. $8^{\text {a }}$ reim. Barcelona: Gedisa.

Giacomello, Corina; Ovalle, Liliana (2006), "La mujer en el 'narcomundo'. Construcciones tradicionales y alternativas del sujeto femenino", Revista de Estudios de Género. La ventana n. 24, pp. 297-318. Universidad de Guadalajara. Consultado en: (23/02/2016).

Gómez, O.I. y Figueroa, A. (2013) Imaginarios sociales de la narcocultura en México: el narcocorrido. En el XXIX Congreso Latinoamericano de Sociología, Santiago de Chile, 29 de septiembre al 4 de octubre http://actacienti fica.servicioit.cl/biblioteca/gt/GT6/GT6_GomezGuzm anFigueroa.pdf

Frutos, M. (2013) Música popular mexicana, y el narco: el riesgo de tocar para "los malos". En portal www.Sine mbargo.mx, 18 de febrero. En línea 15 de abril 2018, disponible en http://www.sinembargo.mx/18-02-2013/5 28400

Malcomson, H. (2019). Negotiating Violence and Creative Agency in Commissioned Mexican Narco Rap. Journal of the Society for Latin American Studies. 38 (3). https://doi.org/10.1111/blar.12977

Mejía E. (2016) Impacto de la guerra del narcotráfico en el rap de Monterrey. El caso de Mexican Fusca. Revista nuestrAmérica 4 (8) julio diciembre, 55-66

Mendoza V.T. (1954) El corrido mexicano. México: CFE (Colección Popular 139)

Mondaca, Anajilda (2012) Narcocorridos, ciudad y vida cotidiana: espacios de expresión de la narcocultura en Culiacán, Sinaloa, México. Tesis doctoral. Guadalajara. ITESO

- (2004) Las mujeres también pueden. Género y narcocorrido. Culiacán. UDO. Monsiváis, C. (2009) Los mil y un velorios. Crónica de la nota roja en México, México. Asociación Nacional del Libro. [1 $\left.1^{\mathrm{a}} \mathrm{ed}, 1994\right]$

Monsiváis C. (2004) "El narcotráfico y sus legiones” en Varios Autores. Viento Rojo, México, Plaza y Janés, 9-44

- (1999) Los mil y un velorios. Crónica de la nota roja en México. México: SEP, CNIE, ANL.

Morin, E. (2015) La maña. Un recorrido antropológico por la cultura de las drogas. México: Debate.

Ochoa A. M. (2006) A manera de introducción: la materialidad de lo musical y su relación con la violencia. En Trans. Revista Transcultural de Música, núm. 10, diciembre. Artículo en línea 15 de febrero 2018, disponible en http://www.redalyc.org/pdf/822/82201001.pdf
Olvera, J. J. (2018) Economías del rap en el noreste de México: emprendimientos y resistencias juveniles alrededor de la música popular. México: CIESAS.

Olvera, J. J. (2016) El rap como economía en la frontera noreste de México. En FRONTERA NORTE, vol. 28, Num. 56, Julio-Diciembre. 85-111

Peña, J.R. (2010) Narco rap, la nueva música de los traficantes mexicanos. En El Espectador, 22 de julio. En línea, disponible el 15 febrero 2017. http://www.elespectador.c om/entretenimiento/agenda/musica/articulo-214735-n arco-rap-nueva-musica-de-los-traficantes-mexicanos

Rincón, O. (2013) Todos llevamos un narco adentro - un ensayo sobre la narco/cultura/telenovela como modo de entrada a la modernidad. En MatrizEs 7, $\mathrm{n}^{\mathrm{O}} 2$. Julio-Diciembre. São Paulo (Brasil), 1-33

Santos, D., A.Vázquez e I. Urgelles (2016) Introducción. Lo narco como modelo cultural. Una apropiación transcontinental. En Mitologías hoy Vol. ${ }^{\circ}$ 14, diciembre 2016, 9-23. Artículo en línea 20 enero 2017, disponible en http://dx.doi.org/10.5565/rev/mitologias.401

Simonett H. (2004) En Sinaloa nací. Historia de la música de banda. Mazatlán- Asociación de Gestores del Patrimonio Histórico y Cultural.

Ross, Alex (2016) Cuando la música es violencia. En Nexos, 1 de octubre. Artículo en línea 1 de abril, disponible en https://www.nexos.com.mx/?p=29704

Secretaría de Seguridad Pública (SSP) (2009).Jóvenes y Narcocultura. México: Subsecretaría de Prevención y Participación Ciudadana Dirección General de Prevención del Delito y Participación Ciudadana.

Thompson J. B. (2002) Ideología y cultura moderna. Teoría crítica social en la era de la comunicación de masas. $2^{\mathrm{a}}$ ed, $1^{\mathrm{a}}$. Reimp. México: UAM.

Valencia S. (2012) Capitalismo Gore y necropolítica en México contemporáneo. En Relaciones Internacionales, núm. 19, febrero de 2012, GERI - UAM. Artículo en línea 7 de mayo 2017, disponible enwww.relacionesinte rnacionales.info

(2010) Capitalismo gore. Control económico, violencia y narcopoder, España: Melusina.

Valenzuela, J. M. (2002) Jefe de Jefes. Corridos y narco-cultural en México, México, Raya en el Agua / Plaza y Janes.

Wald, Elijah, Narcocorrido (2001) A Journey into the Music of Drugs, Guns, and Guerrillas, New York, Harper Collins.

Zavala, Oswaldo (2018) Los cárteles no existen. Narcotráfico y cultura en México. Barcelona. Malpaso Ediciones. 